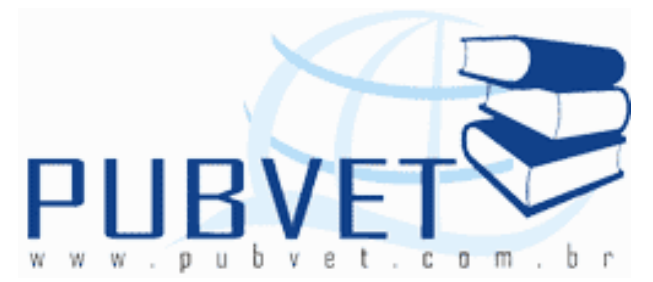

PUBVET, Publicações em Medicina Veterinária e Zootecnia.

\title{
Soroprevalência da artrite encefalite caprina no Município de Alegre/ES, 2012.
}

\section{Alexandre de Oliveira Bezerra ${ }^{1}$, Renan Zappavigna Costa Starling ${ }^{1}$, Igor Luiz Salardani Senhorello ${ }^{1}$, Peter Gabriel Ferreira ${ }^{1}$, Renata Côgo Clipes $^{2}$ e Dirlei Molinari Donatele ${ }^{1}$}

1 Universidade Federal do Espírito Santo, Departamento de Medicina Veterinária; Alegre; Espírito Santo; Brasil.

${ }^{2}$ Instituto Federal do Espírito Santo; IFES-Campus Alegre; Espírito Santo; Brasil.

\section{Resumo}

A artrite encefalite caprina (CAE) é uma enfermidade viral multissistêmica que afeta principalmente os sistemas nervoso, articular e mamário, acarretando grandes prejuízos econômicos. Com o presente trabalho teve-se como objetivo avaliar a prevalência da artrite encefalite caprina no rebanho caprino do município de Alegre/ES, e os fatores de risco para ocorrência dessa doença. Foram selecionadas aleatoriamente sete propriedades no município, e aplicadas entrevistas socioeconômica e de manejo da propriedade. Amostras de sangue foram coletadas de todos os caprinos com mais de seis meses de idade, armazenadas e enviadas ao Laboratório de Inspeção de Produtos de Origem Animal CCA-UFES, para realização do teste sorológico de imunodifusão em gel de Agar (IDGA-Biovetech $®$ ), seguindo todas as orientações do 
fabricante. Foram avaliados soro de 156 animais, de sete propriedades, no qual 12 animais foram sororeagentes, contabilizando uma prevalência de $7,69 \%$ da CAE no município de Alegre. As principais variáveis avaliadas (manejo reprodutivo, participação de feiras eventos, presença de assistência técnica, presença de banco de colostro, tratamento térmico do colostro, tipo de ordenha) não apresentaram significância estatística $(p>0,05)$ para ocorrência da $C A E$, sendo necessários mais estudos na tentativa de elucidar os possíveis fatores de risco que favoreçam a ocorrência da doença na região. Apesar da baixa soroprevalência encontrada no munícipio de Alegre/ES, esforços devem ser dirigidos na tentativa de implantar medidas de controle e prevenção da enfermidade.

Palavras-chave: sanidade. caprinocultura. produtividade.

\title{
Seroprevalence of caprine arthritis encephalitis in municipality of Alegre/ES, 2012.
}

\begin{abstract}
The caprine arthritis encephalitis (CAE) is a multisystemic viral disease that primarily affects the nervous, articulate and breast, causing great economic losses. This study aimed to evaluate the occurrence of caprine arthritis encephalitis in goat herd in the municipality of Alegre / ES, and risk factors for such disease. Randomly selected seven properties in the city, interviews and applied socioeconomic and management of the property. Blood samples were collected from all goats over six months old, stored and sent to the Laboratory of Inspection of Animal Products CCA-UFES for routine HIV testing of Agar gel immunodiffusion (AGID-Biovetech $®$ ) , following the instructions of the manufacturer. We evaluated sera from 156 animals from seven properties, in which 12 animals were reactive serum, accounting for a prevalence of $7.69 \%$ of CAE in the municipality of Alegre. The main variables evaluated (reproductive management, participation in events, the presence of technical
\end{abstract}


BEZERRA, A.O. et al. Soroprevalência da artrite encefalite caprina no Município de Alegre/ES, 2012. PUBVET, Londrina, V. 8, N. 21, Ed. 270, Art. 1801, Novembro, 2014.

assistance, the presence of stock colostrum, colostrum thermal treatment, type of milking) were not statistically significant $(p>0.05)$ for the occurrence of $C A E$, which required further studies to elucidate the possible risk factors that favor the occurrence of disease in the region. Despite the low seroprevalence in the municipality of Alegre/ ES, efforts should be directed in an attempt to implement control measures and prevention of disease.

Keywords: health. goat breeding. productivity.

\section{INTRODUÇÃO}

O Brasil apresentou, nos últimos anos, um crescimento considerável na produção de carne e leite de cabras (FAO, 2012), possuindo o Estado do Espírito Santo 17.897 cabeças de caprinos, classificando o Estado em $23^{\circ}$ lugar na produção nacional de caprinos (IBGE, 2010a), sendo que o município de Alegre, localizado no sul do Estado, possui 545 cabeças (IBGE, 2010b). O setor apresenta elevado potencial para desenvolvimento, sendo 0 manejo inadequado um empecilho para tais melhorias na produção (ROCHA et al., 2009).

A caprinocultura é uma atividade explorada no mundo inteiro, sendo, na maioria das vezes, desenvolvida de forma empírica e extensiva (OLIVEIRA, 2007). Segundo França et al. (2011), o novo perfil do mercado consumidor de produtos provenientes da caprinocultura, vem exigindo uma profissionalização do produtor, sendo necessário realizar mudanças de caráter ambiental e gestacional, incentivando a realização de práticas que, aumentando a produtividade e densidade animal, eleva a ocorrência de doenças infecciosas, como a Artrite Encefalite Caprina (CAE) (OLIVEIRA, 2007).

O surgimento de doenças em qualquer região esta relacionada com o aumento da movimentação de pessoas e animais, modificações ambientais e tecnológicas e a ausência de planos sanitários (BROWN, 2001; ALBUQUERQUE, 2008). 
A artrite encefalite caprina é uma síndrome degenerativa progressiva lenta, multissistêmica, afetando principalmente os sistemas nervoso, articular e mamário, acarretando grandes prejuízos, pela perda dos animais (morte ou descarte), pela diminuição da produção (ROSA, 1996), perda de peso e predisposição a infecção por parasitas gastrointestinais, principalmente nas épocas de chuvas, e gastos com tratamentos devido a maior suscetibilidade a outras enfermidades (PAULA et al., 2008).

O manejo sanitário inadequado ou ausente favorece a ocorrência de doenças infecciosas, tornando fundamental identificar as principais doenças que acometem essas criações, os fatores de risco e medidas que podem ser tomadas para evitar a disseminação do agente causador da enfermidade (ALBUQUERQUE, 2008). A CAE consta na lista de doenças de notificação obrigatória da Organização Mundial de Saúde Animal (OIE), ressaltando a importância da identificação da doença na região (OIE, 2011a).

Com o presente trabalho teve-se como objetivo avaliar a prevalência de artrite encefalite caprina no rebanho caprino do município de Alegre/ES, e os possíveis fatores de risco para ocorrência da doença.

\section{MATERIAIS E METÓDOS}

As propriedades foram selecionadas aleatoriamente, por meio do cadastro das mesmas na Secretaria Municipal de Agricultura no município de Alegre/ES, totalizando sete propriedades.

Foi aplicada a todos os responsáveis pelas propriedades, uma entrevista socioeconômica, abordando as variáveis relativas aos dados da propriedade, nível tecnológico, produção de leite, controle e sanidade dos animais, origem da água da propriedade, procedimentos de ordenha e assistência técnica, para posterior associação com os dados sorológicos obtidos.

Cada propriedade possuiu uma ficha de acompanhamento durante o experimento, na qual foram registrados todos os resultados. Foram coletados, 
de cada animal com mais de seis meses de idade, $5 \mathrm{~mL}$ de sangue total, por meio da punção da veia jugular, em tubos a vácuo estéreis sem anticoagulante, identificadas, acondicionadas em caixa isotérmica com gelo e enviadas ao Laboratório de Inspeção de Produtos de Origem Animal do CCA/UFES, para sorologia da Artrite Encefalite Caprina. Na chegada ao laboratório os tubos de sangue foram centrifugados a $1.500 \mathrm{G}$ durante 10 minutos para obtenção do soro, que foi transferido para tubos tipo eppendorf e congelado até realização do teste sorológico.

O teste sorológico usado foi o de imunodifusão em gel de Agar (IDGA), seguindo rigorosamente as recomendações do fabricante (Biovetech - Kit para diagnóstico de $\left.C A E^{\circledR}\right)$. A leitura foi realizada após 48-72 horas, com luz indireta sobre fundo escuro, considerando definitiva a ultima leitura. Foram consideradas reações positivas as que apresentaram uma linha de precipitação esbranquiçada e uniforme entre o poço teste e o antígeno, e que apresentou identidade com a linha formada pelo soro padrão.

Os dados foram armazenados em um banco de dados no programa Microsoft Excel 2010. Foi utilizada a estatística descritiva e as associações entre as variáveis foram testadas pelo qui-quadrado à nível de significância de $5 \%$.

\section{RESULTADO E DISCUSSÃO}

As amostras foram coletadas em sete propriedades, totalizando 156 animais, selecionando apenas os animais maiores de seis meses. Dessas sete propriedades, três eram produtoras de leite, outras três de produção mista (corte e leite) e apenas uma produtora de caprinos para corte. Das 156 amostras de soro submetidas ao teste IDGA para pesquisa de anticorpos antiCAEV, apenas 12 foram positivas ao teste, contabilizando uma soroprevalência de $7,69 \%$ para CAE no Munícipio de Alegre/ ES.

De acordo com Reina et al. (2009), o rebanho caprino pode ser 
BEZERRA, A.O. et al. Soroprevalência da artrite encefalite caprina no Município de Alegre/ES, 2012. PUBVET, Londrina, V. 8, N. 21, Ed. 270, Art. 1801, Novembro, 2014.

classificado de acordo com a soroprevalência para CAE em: elevada (> 70\%), intermediário $(40-69 \%)$, baixa $(10-39 \%)$, muito baixa $(1-9 \%)$ e negativo (Livre de Lentivirus de Pequenos Ruminantes). Portanto, a soroprevalência no município de Alegre/ES, pode ser considerada muito baixa (1 - 9\%), não descartando a necessidade de implantar medidas sanitárias para controle da enfermidade, pois esta é uma doença amplamente distribuída, de importância mundial, de notificação obrigatória aos órgãos locais de defesa sanitária animal (OIE, 2011a), e, devido a suas várias vias de transmissão, possibilita a disseminação da doença para outros caprinos (BLACKLAWS et al., 2004).

A prevalência nesse estudo $(7,69 \%)$ é semelhante à encontrada por Sell (2000), em Santa Catarina (6,72\%), e por Bandeira et al. (2009), na Paraíba $(8,2 \%)$. Assim como relatado por Sell (2000), apesar da falta de conhecimento da importância da doença e pouco empenho, por parte do produtor, em aplicar medidas sanitárias de controle para evitar a doença, a prevalência encontrada foi baixa, mas providencias devem ser tomadas no intuito de evitar que a situação se agrave futuramente.

Segundo França et al. (2011), com as novas exigências do mercado consumidor, são necessárias mudanças do produtor de caráter ambiental e gestacional. O surgimento de novas doenças tem sido relacionado a alguns fatores, como: aumento do transito de animais e pessoas; alterações no meio ambiente/transformações tecnológicas; doença acometendo mais que uma espécie; e ausência de planos sanitários de controle (BROWN, 2001), proporcionando condições favoráveis para disseminação da CAE (OLIVEIRA, 2007), existindo uma correlação entre o aumento do nível tecnológico e a ocorrência da doença (SILVA et al., 2005). A criação de caprinos no município de Alegre é predominantemente de baixa produtividade e pouca tecnificação, sendo predominante o manejo extensivo ou semi-intensivo, podendo ser uma das razões para baixa prevalência encontrada, pois como discutido por Pinheiro et al. (2004) e Sobrinho et al. (2010) a CAE afeta principalmente rebanhos leiteiros de alta produção. 
BEZERRA, A.O. et al. Soroprevalência da artrite encefalite caprina no Município de Alegre/ES, 2012. PUBVET, Londrina, V. 8, N. 21, Ed. 270, Art. 1801, Novembro, 2014.

A caprinocultura apresenta grande potencial para crescimento, mas a falta de um manejo adequado é uma das principais barreiras para melhorias dos índices de produção e, consequentemente, aumento da renda do produtor rural (ROCHA et al., 2009).

No presente estudo, do total de animais (156), apenas nove eram machos, sendo todos esses soronegativos para o vírus da CAE. Segundo Lara et al. (2005) a CAE afeta caprinos de qualquer idade, independente do sexo, raça ou produção. Bandeira et al. (2009), encontraram a CAE distribuída em vários municípios paraibanos, onde, dos 15 municípios estudados, 13 possuíam pelo menos um animal soropositivo. Porém, o estado da Paraíba como um todo, possui uma baixa taxa de animais soropositivos, com apenas $8,2 \%$ (42/600) de soroprevalência no estado. Nesse estudo, Bandeira et al. (2009), notaram uma maior ocorrência da infecção em machos, justificando este achado pela grande rotatividade de machos reprodutores dos rebanhos, adquiridos muitas vezes de áreas endêmicas do Brasil.

No Estado do Tocantins também foi observada uma baixa soroprevalência, com apenas 2,3\% (23/843) das amostras positivas no teste IDGA, isso se deve a recente formação do rebanho caprino na região, e a não realização de práticas que aumentem o risco de transmissão da doença, como utilização de mamadeira coletiva e confinamento dos animais (SOBRINHO et al., 2010), práticas essas semelhante ao manejo encontrado no município de Alegre/ES, no presente estudo.

Em Pernambuco a soroprevalência encontrada foi de 3,8\%, sendo considerada muito baixa, não havendo relação com a faixa etária ou sexo dos animais (OLIVEIRA et al., 2006). No Ceará, após avaliação de 4019 animais em 130 propriedades, foi encontrada prevalência de $1 \%$, observando maior ocorrência na região metropolitana de Fortaleza. Das 130 propriedades, 12 $(9,2 \%)$ apresentaram animais infectados pelo vírus da $C A E$, sendo todas as propriedades que possuíam um manejo intensivo de criação positivas para CAE (PINHEIRO et al., 2004), diferindo do manejo observado nas propriedades do 
BEZERRA, A.O. et al. Soroprevalência da artrite encefalite caprina no Município de Alegre/ES, 2012. PUBVET, Londrina, V. 8, N. 21, Ed. 270, Art. 1801, Novembro, 2014.

presente estudo, sendo predominante o manejo extensivo a semi-intensivo, o que pode ter contribuído para baixa prevalência encontrada.

Observou-se que a doença está amplamente disseminada nas diversas microrregiões da Bahia, encontrando prevalência de 13,4\% para o estado, notando uma maior ocorrência em fêmeas $(90,23 \%)$ e animais adultos $(89,77 \%)$ (ALMEIDA, 2001). No Rio Grande do Norte foram avaliados 11 municípios, sendo encontrada em todos eles a ocorrência da CAE, com uma prevalência média de $11 \% \pm 1,5 \%$, relacionando uma maior tecnificação das criações com uma pior qualidade sanitária do rebanho. Os fatores de risco encontrados foram: compra de animais para reposição ou ampliação do rebanho feita sem exigências sanitárias; sala de ordenha, aglomerando os animais; locais fechados na ocasião do parto; cabras de alta produção, mais susceptíveis a infecção (SILVA et al., 2005).

Em São Paulo foi encontrado uma prevalência de 43,01\% e 34, 93\% nos anos 2004 e 2007, respectivamente (LEITE et al., 2004; MADUREIRA; GOMES, 2007). Segundo Madureira e Gomes (2007), a alta prevalência no estado é devido a continua aquisição de novos animais sem avaliação dos critérios sanitários. A compra e introdução de novos animais no plantel deve respeitar um período de quarentena de até seis meses, devendo, nesse período, serem realizados dois testes para lentiviroses (BRASIL, 2004).

Apenas uma propriedade apresentou animais soropositivos para CAEV, possuindo prevalência de 28,57\% (12/42) na mesma. O que, segundo Reina et al. (2009), é uma soroprevalência baixa (entre 10 - 39\%), não retirando a importância da presença da doença nesse rebanho, necessitando implantar medidas de controle e prevenção. Como indicação do programa de controle, sugere-se o abate dos animais positivos (PLAZA et al., 2009) ou o isolamento (NORD et al., 1998), e restrição da movimentação destes entre as instalações, de acordo com a necessidade de cada produtor, evitando a perda de grande número de animais (REINA et al., 2009). A partícula viral livre permanece infectante por pouco tempo no ambiente, porém pode sobreviver durante 
BEZERRA, A.O. et al. Soroprevalência da artrite encefalite caprina no Município de Alegre/ES, 2012. PUBVET, Londrina, V. 8, N. 21, Ed. 270, Art. 1801, Novembro, 2014.

longo tempo dentro da célula hospedeira, como em sangue e fluidos orgânicos, possibilitando a transmissão horizontal da doença (NARAYAN; CLEMENTS, 1989). Nord et al. (1998) relatam que apenas a limpeza mecânica das instalações pode ser suficiente para eliminar o vírus, podendo realizar a desinfecção utilizando-se compostos fenólicos ou de amônio quaternário. Medidas de desinfecção e assepsia de materiais cirúrgicos devem ser adotadas, evitando-se transmissão iatrogênica da doença (REILLY et al., 2004). Por fim, a certificação de uma propriedade como livre de lentiviroses é feita utilizandose as técnicas de PCR e Western Blot (BRASIL, 2004), o que difere do exigido pela OIE, que padroniza como testes sorológicos IDGA e ELISA (OIE, 2012b).

As variáveis testadas por meio da entrevista foram: manejo reprodutivo (monta natural ou inseminação artificial); programa de vacinação; participação de feiras e eventos; presença de assistência técnica; presença de banco de colostro; tratamento térmico do colostro; tipo de ordenha; realiza linha de ordenha; e higiene durante a ordenha. Nenhuma das variáveis testadas apresentou significância estatística $(p>0,05)$, isso provavelmente devido ao manejo muito parecido entre as propriedades e a baixa prevalência da doença nas localidades estudadas.

Quanto ao manejo reprodutivo, todas as propriedades realizavam a monta natural. O vírus da CAE possui potencial para ser transmitida via acasalamento ou inseminação artificial com sêmen infectado, pois, utilizando PCR, foi detectado o DNA proviral no trato genital feminino (útero e cornos uterinos) sete dias após monta ou inseminação artificial. Porém, ainda não é possível afirmar que essa via de transmissão resulte em novas infecções (AHMAD et al., 2012b). Como relatado por Peterson et al. (2008), maior atenção deve ser dada ao manejo sanitário-reprodutivo destes animais, sendo que, para os machos reprodutores ou doadores de sêmen, O PCR de amostras de sangue é um coadjuvante essencial, utilizado em associação com teste imunológico, para a comprovação da infecção do vírus no animal. Segundo Andrioli et al. (2006), em um programa de controle da CAE, é fundamental a 
BEZERRA, A.O. et al. Soroprevalência da artrite encefalite caprina no Município de Alegre/ES, 2012. PUBVET, Londrina, V. 8, N. 21, Ed. 270, Art. 1801, Novembro, 2014.

identificação do DNA proviral no sêmen dos reprodutores, considerando o risco da transmissão tanto por meio da monta natural como por meio da inseminação artificial.

Nenhuma propriedade possuía programa de vacinação, demonstrando a ausência de planos sanitários para controle de qualquer enfermidade infecciosa, como ressaltado por Albuquerque (2008), a implantação de um programa sanitário é fundamental para evitar a introdução e disseminação de novos agentes infecciosos no rebanho (ALBUQUERQUE, 2008). Apesar da ausência de vacinas ou tratamentos efetivos para controle da CAE (BELKNAP, 2004; REINA et al., 2009), e considerando a grande perda econômica decorrente dessa enfermidade, esforços devem ser dirigidos para evitar a ocorrência de novos casos, através da adoção de medidas de prevenção e controle da doença, melhorando, consequentemente, a produtividade (BOHLAND; D'ANGELINO, 2004) da caprinocultura no munícipio de Alegre/ES.

Além disso, nenhuma das propriedades produtoras de leite possuía um programa de higiene durante a ordenha, possibilitando a ocorrência de transmissão iatrogênica através da ordenhadeira mecânica ou das mãos do ordenhador, passando de um animal para outro, como discutido por Blacklaws et al. (2004) como uma possível via de transmissão. Apesar da não adoção de medidas de higiene durante a ordenha, esse não representou fator de risco para transmissão da $\mathrm{CAE}$, isso provavelmente devido ao baixo número de animais soropositivos encontrados. Além disso, a média de produção das cabras avaliadas foi de 0,5 L/leite/dia, sendo animais de baixa produção diária, oque vem de encontro com o relatado por Pinheiro et al. (2004) que observaram maior ocorrência em animais de alta produção. Recomenda-se que o produtor realize a linha de ordenha mantendo a seguinte ordem: ordenhar primeiro as fêmeas jovens negativas; em segundo as fêmeas adultas negativas; e, por fim, as fêmeas positivas (BRASIL, 2004).

Somente a propriedade positiva para CAEV, levava os animais para participação de feiras e eventos, o que, segundo Brown (2001), além de outros 
BEZERRA, A.O. et al. Soroprevalência da artrite encefalite caprina no Município de Alegre/ES, 2012. PUBVET, Londrina, V. 8, N. 21, Ed. 270, Art. 1801, Novembro, 2014.

fatores, o aumento do transito de animais e pessoas pode favorece o surgimento de novas doenças na região. Apenas essa propriedade realiza o tratamento térmico do colostro (pasteurização), podendo a ingestão do colostro não ser a principal via de transmissão nessa propriedade, o que corrobora com Leitner et al. (2010) que afirma que a pasteurização do colostro é uma medida eficaz para não transmissão da doença, a qual deve ser feita a temperatura constante de $56^{\circ} \mathrm{C}$, durante uma hora (BRASIL, 2004).

Apenas uma propriedade possui assistência técnica, totalizando 42 (26,92\%) animais, todos soronegativos para CAE, demonstrando à baixa tecnificação das propriedades.

Apesar da baixa soroprevalência encontrada no município de Alegre/ES, a doença está presente, o que torna necessário mais estudo na tentativa de definir os principais fatores de risco para transmissão e manutenção da doença na região, evitando que esses valores aumentem futuramente. Devido a fácil disseminação da doença, ao grande impacto econômico e as perdas produtivas causadas pela infecção do vírus da CAE em rebanhos caprinos, esforços devem ser dirigidos, na tentativa de implantar medidas sanitárias e de controle dessa enfermidade.

\section{REFERÊNCIAS}

AHMAD, M.Z.A.A.; DUBREIL, L.; CHATAGNON, G.; KHAYLI, Z.; THERET, M.; MARTIGNAT, L.; CHEBLOUNE, Y.; FIENI, F. Goat uterine epithelial cells are susceptible to infection with Caprine Arthritis Encephalitis Virus (CAEV) in vivo. Veterinary Research, v. 43, n. 5, p. 1 - 7, 2012.

ALBUQUeRQUe, I.R.R. Perfil sanitário de rebanho caprino da região de Senhor do Bonfim, Bahia - Brasil. 2008. Monografia (Graduação em Medicina Veterinária) - Centro de Saúde e Tecnologia Rural, Universidade Federal de Campina Grande, Patos.

ALMEIDA, M.G.A.R.; ANUNCIAÇÃO, A. V. M.; FIGUEREDO, A.; MARTINEZ, T. C. N. ; LABORDA,S. S. Dados sorológicos sobre a presença e distribuição da artrite-encefalite caprina (CAE) no Estado da Bahia , Brasil. Revista Brasileira de Saúde e Produção Animal, v. 1, n. 3, p.78-83, 2001.

ANDRIOLI, A.; GOUVEIA, A.M.G.; MARTINS, A.S.; PINHEIRO, R.R.; SANTOS, D.O. Fatores de risco na transmissão do lentivírus caprino pelo sêmen. Pesquisa Agropecuária Brasileira, Brasília, v.41, n.8, p.1313 - 1319, 2006. 
BANDEIRA, D.A.; CASTRO, R.S.; AZEVEDO, E.O.; MELO, L.S.S.; MELO, C.B. Seroprevalence of caprine arthritis-encephalitis virus in goats in the Cariri region, Paraiba state, Brazil. The Veterinary Journal, v. 180, n. 3, p. 399-401, 2009.

BELKNAP, E.B. Enfermidades do Sistema Respiratório. In: PUGH, D.G. Clínica de ovinos e caprinos. São Paulo: Roca, 2004. p. 119 - 143.

BLACKLAWS, B.A.; BERRIATUA, E.; TORSTEINSDOTTIR, S.; WATT, N.J.; ANDRES, D.; KLEIN, D.; HARKISS, G.D. Transmission of small ruminant lentiviruses. Veterinary Microbiology, v. 101, n. 3, p. 199-208, 2004.

BOHLAND, E.; D'ANGELINO, J. L. Artrite-Encefalite Caprina: avaliação dos aspectos produtivos e reprodutivos de animais infectados e não infectados. Brazilian Journal Veterinaria Research Animal Science, v.42, n.2, p.81-88, 2005

BRASIL. Portaria n 103, de 7 de dezembro de 2004. Ministério da Agricultura Pecuária e Abastecimento. Disponível em: <http://extranet.agricultura.gov.br/sislegis>. Acesso em: 06 abr. 2012.

BROWN, C. La importância de las enfermidades emergentes para la sanidad animal, la salud pública y el comercio. OIE, 2001. Disponível em: <ftp://ftp.oie.int/69SG_2001/E_69_SG_9.pdf>. Acesso em: 22 mai 2012.

FAO, Food and Agriculture Organizatio (2012). FAOSTAT - FAO Statistics Division/ Production: Livestock Primary. Disponível em: <http://faostat.fao.org/site/569/default.aspx\#ancor>. Acesso em: 04/05/2012.

FRANÇA, F.M.C.; HOLANDA JUNIOR, E.V.; SOUZA NETO, J.M. Análise da Viabilidade Financeira e Econômica do Modelo de Exploração de Ovinos e Caprinos No Ceará por Meio do Sistema Agrossilvipastoril. Revista Econômica do Nordeste, Fortaleza, v. 42, n. 2, p. 287 - 308, 2011.

IBGE, Estados. Produção da Pecuária, 2010. Disponível em: <http://www.ibge.gov.br/estadosat/temas.php?sigla=es\&tema=pecuaria2010>. Acesso em: 27 abr. 2012. a.

IBGE, Produção da Pecuária Municipal, 2010. Disponível em: <http://www.ibge.gov.br/cidadesat/topwindow.htm?1>. Acesso em: 27 abr. 2012. b.

LARA, M.C.C.S.H.; BIRGEL JUNIOR, E.H.; GREGORY, L.; BIRGEL, E.H. Aspectos clínicos da artrite-encefalite dos caprinos. Arquivo Brasileiro de Medicina Veterinária e Zootecnia, v.57, n.6, p. $736-740,2005$.

LEITE, B.L.S.; MODOLO, J.R.; PADOVANI, C.R.; STACHISSINI, A.V.M.; CASTRO, R.S., SIMÕES, L.B. Avaliação da taxa de ocorrência da artrite-encefalite caprina a vírus pelas regionais do escritório de Defesa Agropecuária do estado de São Paulo, Brasil, e seu mapeamento por meio de Sistema de Informações Geográficas. Arquivo do Instituto Biológico, São Paulo, v.71, n.1, p.21-26, 2004.

LEITNER, G.; KRIFUCKS, O.; WEISBLIT, L.; LAVI, Y.; BERNSTEIN, S.; MERIN, U. The effect of caprine arthritis encephalitis virus infection on production in goats. The Veterinary Journal, v. 183, n. 3, p. 328-331, 2010. 
MADUREIRA, K.M.; GOMES, V. Prevalência da artrite encefalite caprina (CAE) em propriedades leiteiras do Estado de São Paulo. Revista de Ciências Veterinárias, v. 5, n. 5, p. 78 - 83, 2007.

NARAYAN, O.; CLEMENTS, J.E. Biology and Pathogenesis of Lentiviruses. Journal of General Virology,v. 70, n. 7, p. 1617-1639, 1989.

NORD, K.; LOKEN, T.; ORTEN, A . Control of caprine arthritis-encephalitis virus infection in three Norwegian goat herds. Small Ruminant Research, v. 28, n. 2, p. 109-114, 1998.

OIE, Animal health in the World: OIE Listed diseases, 2012. Disponível em: <http://www.oie.int/animal-health-in-the-world/oie-listed-diseases-2012/>. Acesso em: 27 abr. $2012 a$.

OIE. Prescribed and Alternative Diagnostic Tests for OIE Listed Diseases. Disponível em: <http://www.oie.int/index.php?id=169\&L=0\&htmfile=chapitre_1.1.3.htm>. Acesso em: 08/08/2012b.

OLIVEIRA, M.M.M.; CASTRO, R.S.; CARNEIRO, K.L.; NASCIMENTO, S.A.; CALLADO, A.K.C.; ALENCAR, C.S.A.; COSTA, L.S.P. Anticorpos contra lentivírus de pequenos ruminantes em caprinos e ovinos em abatedouros do estado de Pernambuco. Arquivo Brasileiro de Medicina Veterinária e Zootecnia, v.58, v.5, p. 947-949, 2006.

OLIVEIRA, M.M.M. Diagnóstico e controle de Lentivírus de Pequenos Ruminantes (LVPR) em caprinos. 2007. Tese (Doutorado em Ciência Veterinária) - Programa de Pós-Graduação em Ciência Veterinária, Universidade Federal Rural de Pernambuco, Recife.

PAULA, N.R.O.; ANDRIOLI, A.; CARDOS, J.F.S.; SOUZA, F.M.L.; SOUZA, K.C.; PINHEIRO, R.R.; ALVES, F.S.F.; TEIXEIRA, M.F.S. Parâmetros clínicos e hematológicos de reprodutores caprinos infectados naturalmente pelo vírus da artrite encefalite caprina durante a transição da estação seca para chuvosa no ceará. Arquivo Instituto Biológico, v. 75, n. 2, p. 141 - 147, 2008.

PETERSON, K.; BRINKHOF, J.; HOUWERS, D.J.; COLENBRANDER, B.; GADELLA, B.M. Presence of pro-lentiviral DNA in male sexual organs and ejaculates of small ruminants. Theriogenology, v. 69 , n. 4 , p. 433-442, 2008.

PINHEIRO, R.R.; GOUVEIA, A.M.G.; ALVES, F.S.F.; ANDRIOLI, A. Perfil de propriedades no estado do Ceará relacionado à presença do lentivírus caprino. Ciência Animal, v. 14, n. 1, p. 29-37, 2004.

PLAZA, M.; SÁNCHEZ, A.; CORRALES, J.C.; FE, C. D.; CONTRERAS, A. Caprine arthritis encephalitis virus diagnosed by ELISA in lactating goats using milk samples. Small Ruminant Research, v. 81, n. 2 - 3, p. $189-192,2009$.

REILLY, L.K.; BAIRD, A.N.; PUGH, D.G. Enfermidades do Sistema Musculoesquelético. In: PUGH, D.G. Clínica de ovinos e caprinos. São Paulo: Roca, 2004. p. $251-286$.

REINA, R.; BERRIATUA, E.; LUJÁN L.; JUSTE, R.; SÁNCHEZ, A.; ANDRÉS, D.; AMORENA, B. Prevention strategies against small ruminant lentiviruses: An update. The Veterinary Journal, v. 182, n. 1, 2009, p. 31-37.

ROCHA, L.P.; FRAGA, A.B.; ARAÚJO,A.J.T.; FIGUEIRA, B.R.F.; PACHECO, K.M.G.; SILVA, A.F.L.; RODRIGUES, B.E.D.S. Desempenho de Cordeiros Cruzados Em Alagoas, Brasil. Archivos de Zootecnia, v. 58, n. 221, p. 145 - 148, 2009. 
ROSA, J.S. Enfermidades em caprinos: diagnóstico, patogenia, terapêutica e controle. Brasília: Embrapa - SPI, 1996.

SELL, B.E. Prevalência de anticorpos para o vírus da artrite-encefalite caprina em soros de caprinos no estado de Santa Catarina. 2000. Monografia (Especialização em Sanidade Animal) - Programa de Pós-graduação do Centro de Ciências Agroveterinárias, Universidade do Estado de Santa Catarina, Lages.

SILVA, J.S.; CASTRO, R.S.; MELO, C.B.; FEIJÓ, F.M.C. Infecção pelo vírus da artrite encefalite caprina no Rio Grande do Norte. Arquivo Brasileiro de Medicina Veterinária e Zootecnia, v.57, n.6, p.726-731, 2005.

SOBRINHO, P.A.M.; RAMOS, T.R.R.; FERNANDES, C.H.C.; CAMPOS, A.C.; COSTA, L.M.; CASTRO, R.S. Prevalência e fatores associados à infecção por lentivírus de pequenos ruminantes em caprinos no estado do Tocantins. Ciência Animal Brasileira, Goiânia, v. 11, n. 1 , p. $117-124,2010$. 